\title{
Productivity, Oil Content, Composition, and Bioactivity of Oil-bearing Rose Accessions
}

\author{
Natasha Kovatcheva ${ }^{1}$ \\ Research Institute for Roses, Aromatic and Medicinal Crops, Kazanlak, \\ Bulgaria
}

Valtcho D. Zheljazkov ${ }^{2,4}$
University of Wyoming, Sheridan Research and Extension Center, 663
Wyarno Road, Sheridan, WY 82801

Tess Astatkie ${ }^{3}$

Nova Scotia Agricultural College, 50 Pictou Road, Truro, Nova Scotia B2N 5E3, Canada

Additional index words. Rosa damascena, Rosa gallica, Rosa centifolia, Rosa alba, essential oil content, essential oil composition

\begin{abstract}
Rose oil production worldwide is based on different oil-bearing Rosa species. This 4-year study determined the essential oil content, constituents, and morphologic/phenologic characteristics of 25 varieties, chemotypes, and hybrids belonging to five Rosa species ( $R$. damascena Mill., $R$. gallica $\mathbf{L}$., $R$. centifolia $\mathrm{L}$., and $R$. alba $\mathrm{L}$.). Limits of variation of these indices were established for each variety, chemotype, and hybrid group. The essential oil content of $R$. damascena varied from $0.032 \%$ to $0.049 \%$ and that of hybrid roses from $\mathbf{0 . 0 3 7 \%}$ to $\mathbf{0 . 0 5 \%}$. The highest essential oil content was found in $R$. damascena accession Svejen 74 and the lowest in $R$. alba. Within $R$. damascena, the weight of single flowers varied from 2.09 to $3.44 \mathrm{~g}$, the number of petals from 22 to 28 , the height of the plants from 61 to $128 \mathrm{~cm}$, and the diameter of bushes from 53 to $118 \mathrm{~cm}$. $R$. centifolia had the largest flowers. The essential oil of the various species showed moderate to no antimicrobial activity at $50 \mu \mathrm{g} / \mathrm{mL}$ and no significant antibacterial, antifungal, antileishmania, or antimalarial activity at this concentration. All the tested species and accessions could be grown in Bulgaria (and possibly in southeastern Europe and the northern Mediterranean) and provide comparable productivity to the traditional species $R$. damascena. Wide variations occurred in essential oil content and constituents and morphologic/phenologic characteristics of the tested Rosa species and accessions. The availability of various species and chemotypes within specific species offer an opportunity for production of oilbearing roses and essential oils to meet market requirements of specific rose oils.
\end{abstract}

Approximately 400 species belong to the family Rosaceae; however, few of them have been used for production of rose essential oil (Topalov, 1978). Bulgaria has more than 330 years of tradition in rose oil production, and the oil-bearing rose is the most important

Received for publication 4 Jan. 2011. Accepted for publication 9 Mar. 2011.

This research was partially funded by the Bulgarian Ministry of Education awarded to Dr. Kovatcheva and by startup funds from the University of Wyoming provided to Dr. Zheljazkov.

We thank Dr. Charles L. Cantrell from the National Center for Natural Products Research for the antimicrobial and antibacterial activity of the oils.

The antimicrobial, antibacterial, antileishmania, and antimalarial activities of the rose essential oils from this study were conducted at the National Center for Natural Products Research at the University of Mississippi.

${ }^{1}$ Senior Researcher.

${ }^{2}$ Asssociate Professor.

${ }^{3}$ Professor

${ }^{4}$ To whom reprint requests should be addressed; e-mailvaltcho.pubs@gmail.com. have been selected for possible cultivar development and have not been investigated.

Although several rose species lie within a number of chemotypes, currently the Kazanlak rose $(R$. damascena $)$ is the only species used for commercial rose oil production in Bulgaria (Nedkov and Attanassova, 2004; Zheljazkov et al., 1996). It is a complex natural hybrid, and seed progeny do not provide plants with valuable characteristics for the industry (Topalov, 1978). Hence, the oil-bearing roses have been and still are propagated by vegetative means through rooted cuttings (Nedkov and Attanassova, 2004; Topalov, 1978; Zheljazkov, 1998).

The presence of various phenotypes and chemotypes allows for selection of clones (and subsequently cultivars) with high productivity and various chemical compositions. Worldwide, rose oil production is based on several species: Rosa damascena Mill., Rosa gallica L., Rosa centifolia L., and Rosa alba L. (Rusanov et al., 2005a; Tabaei-Aghdaei et al., 2007; Topalov, 1978); however, comparative studies of these species under the same ecological conditions have not been reported. The objective of this study was to compare the essential oil content, constituents, and morphologic/phenologic characteristics of 25 varieties, chemotypes, and hybrids belonging to the five Rosa species listed previously. In addition, we evaluated the antimicrobial activity of the essential oil from these species.

\section{Materials and Methods}

Plant materials and growing conditions. Twenty-five clones and cultivars were used (Table 1). Of these, 18 clones and one cultivar belonged to $R$. damascena Mill. $f$. trigintipetala Dieck. developed using various methods, including selection of natural spontaneous mutations from the Kazanlak oil-bearing rose population (Table 1). The selected clones were chosen using molecular markers and identified as belonging to $R$. damascena Mill. (Rusanov et al., 2005b; Todorova et al., 2004). We also included three rose species used for commercial oil production in other countries (Table 1). Cultivar Kooperatorka was developed by Maichenko (Nedkov and Attanassova, 2004). Cultivar Iskra from $R$. damascena was used as the standard.

The field experiments were conducted in the experimental fields of the Research Institute for Roses and Medicinal Plants in Kazanlak, Bulgaria, during the 2000 to 2004 cropping seasons using a randomized complete block design with three blocks. Individual plots were $16 \mathrm{~m}^{2}$ with 20 rose bushes in every plot planted at $0.8 \mathrm{~m}$ within row and 2.8 $\mathrm{m}$ between rows to reflect common agricultural practices of rose production in the region. To eliminate border effects, of the 20 plants in each individual plot, only the 10 inside plants were harvested. Plants from all clones and cultivars were propagated through rooting of green cuttings in greenhouses in the spring of 2000 following the established protocol for the production of standard rose cuttings (Zlatev et al., 2001) and transplanted in the field in Nov. 2000. However, because rose bushes do 
not flower during the first growing season (2001), data were not available for 2001. During the four cropping seasons (2001 to 2004), a standardized agricultural protocol developed by the researchers at the Research Institute for Roses and Medicinal Plants for industrial rose plantations was used (Kovatcheva et al., 2004; Nedkov and Attanassova, 2004). Soil was deluvial-meadow sandy (European Digital Archive of Soil Maps of the World, 2009) with relatively low concentrations of available nutrients and $\mathrm{pH}$ of 4.9 in the soil profile 0 to 20 $\mathrm{cm}$ and $\mathrm{pH}$ of 5.09 in the deep soil profile 20 to $40 \mathrm{~cm}$.

Biometrical measurements, oil content, and oil composition analysis. Plant height, plant diameter, number of flowering buttons per flowering branch, weight, diameter, number of developed and undeveloped petals per individual flower, and essential oil content were taken every year at flowering by picking the rose flowers in early morning (0500 to $0700 \mathrm{HR}$ ) when the content and composition of the essential oil are optimal (Topalov, 1962, 1978).

The essential oil content from each plot was measured using samples of $600 \mathrm{~g}$ fresh flowers through water distillation in Clevengertype glass distillation equipment (Furnis et al., 1989; Topalov, 1962). The essential oil obtained was measured in cubic millimeters, multiplied by 0.85 , which is the relative weight of the rose oil (Topalov, 1962), and was calculated as percentage of oil content in $100 \mathrm{~g}$ fresh flowers. Rose oil from the field experiments and the chemical standards were analyzed by gas chromatograph (GC) PYE Unicam. The GC was equipped with a EKONO-CAP ${ }^{\text {TM }} \mathrm{EC}^{\mathrm{TM}}$-1 fused silica capillary column $(30 \mathrm{~m} \times 0.32$ $\mathrm{mm}$ ) operated under the following conditions: injector temperature $300{ }^{\circ} \mathrm{C}$, column temperature, 70 to $230{ }^{\circ} \mathrm{C}$ at $8{ }^{\circ} \mathrm{C} \cdot \mathrm{min}^{-1}$, then held at $230^{\circ} \mathrm{C}$ for $5 \mathrm{~min}$; carrier gas, hydrogen at 1.3 $\mathrm{mL} \cdot \mathrm{min}^{-1}$ flow rate; injection volume of $0.1 \mu \mathrm{L}$ (splitless). Internal chemical standards were used to identify and quantify the individual constituents. The GC analyses identified the major and some minor oil constituents as required by the international standard ISO 9842-2004.

Antimicrobial, antimalarial, and antileishmania activity and cytotoxicity. Assays for antimicrobial, antimalarial, and antileishmania activity and cytotoxicity were performed as described previously (Mikus and Steverding, 2000; Zheljazkov et al., 2008). As a result of the high costs of conducting these assays, at least one representative essential oil sample from each rose species $[R$. damascena $\times R$. gallica, $R$. gallica subsp. Eriostyla var. austriaca, $R$. damascena ( $R$. kazanlika), $R$. centifolia, $R$. alba, and $R$. gallica] was tested for antifungal, antimicrobial, antimalarial, and antileishmania activity against a panel of human pathogens in an in-house testing facility at the National Center for Natural Products Research at the University of Mississippi. In the primary in-house screens for antimicrobial, antifungal, antileishmania, and antimalarial activity, none of the samples showed greater than $50 \%$ growth inhibition of the tested organisms at 50 $\mu \mathrm{g} / \mathrm{mL}$ and were therefore deemed to be inactive.

Statistical analyses. Essential oil content response was analyzed as a randomized complete block design with 25 treatments (19 clones, three hybrids, and three species) and nine blocks. The blocks were combinations of the three blocks in the field and the 3 years. The analysis of variance was completed using the GLM procedure of SAS 9.2 (SAS Institute Inc., 2008). Because the effect of treatment was highly significant with a $P$ value $<0.001$ multiple means comparison was done using the least significant difference method to generate letter groupings at the $5 \%$ level of significance. The validity of normal distribution and constant variance assumptions on the error terms was also verified.

Table 1. List of the rose species, hybrids, and accessions used in this study with indication of the methods they were developed.

\begin{tabular}{ll}
\hline Species, accession & Developed, specification \\
\hline R. damascena & Radiation mutagenesis \\
601 & Radiation mutagenesis \\
1151 & Chemical mutagenesis \\
831 & Chemical mutagenesis \\
101 & Natural spontaneous mutations \\
$148 / 75$ & Natural spontaneous mutations \\
$6 / 79$ & Natural spontaneous mutations \\
$7 / 79$ & Natural spontaneous mutations \\
$70 / 74$ & Natural spontaneous mutations \\
K-4 & Traditional selection in the towns of \\
Svejen 188 & Aleksandrovo and Svejen \\
& Traditional selection in the towns of \\
Svejen 74 & Aleksandrovo and Svejen \\
& Traditional selection in the towns of \\
Svejen 72 & Aleksandrovo and Svejen \\
& Traditional selection in the towns of \\
Aleksandrovo 112 & Aleksandrovo and Svejen \\
& Traditional selection in the town of Kazanlak \\
51 & Individual selection from 4 high-yielding \\
Population N ${ }^{\circ} 5$ & clones in Kazanlak \\
& Control cultivar \\
Iskra & Traditional selection in the town of Kazanlak \\
1071 & Traditional selection in the town of Kazanlak \\
$N^{\circ} 809$ & Traditional selection in the town of Kazanlak \\
$9 / / 77$ & \\
& \\
Hybrids & Hybridization $(R$. gallica L. Subsp. \\
$836 / / 61$ hybrid & eriostyla Kell. var. austriaca Crants. $f$. Panonica \\
& $\times R$. damascena $) \times R$. damascena \\
$90 / 67$ hybrid & Hybridization between $R$. damascena and $R$. gallica \\
cv. Kooperatorka & Hybridization between $R$. damascena and $R$ gallica \\
&
\end{tabular}

Species that are also used for commercial production of rose oil in some countries

R. centifolia

R. gallica, cv. K. tchervena

R. alba

Table 2. Average monthly temperatures and rainfall for the four growing seasons in Kazanlak, Bulgaria.

\begin{tabular}{|c|c|c|c|c|c|c|c|}
\hline $\mathrm{Yr} / \mathrm{mo}$. & January & February & March & April & May & June & July \\
\hline \multicolumn{8}{|c|}{ Average monthly temperatures $\left({ }^{\circ} \mathrm{C}\right)$} \\
\hline 2001 & 1.6 & 3.1 & 9.2 & 10.7 & 15.5 & 18.8 & 23.9 \\
\hline 2002 & -0.1 & 5.9 & 7.3 & 9.5 & 15.6 & 20.5 & 23.0 \\
\hline 2003 & -1.3 & -2.3 & -3.5 & 9.2 & 18.1 & 21.6 & 22.7 \\
\hline 2004 & -1.4 & 2.3 & 6.3 & 10.9 & 14.1 & 19.0 & 21.1 \\
\hline \multicolumn{8}{|c|}{ Average monthly rainfall $(\mathrm{mm})$} \\
\hline 2001 & 55.4 & 20.2 & 43.5 & 74.0 & 55.6 & 67.1 & 27.3 \\
\hline 2002 & 9.4 & 8.8 & 73.1 & 23.7 & 51.4 & 45.6 & 215.6 \\
\hline 2003 & 53.2 & 9.6 & 8.5 & 17.4 & 41.4 & 27.5 & 66.5 \\
\hline 2004 & 37.6 & 6.6 & 13.2 & 3.4 & 22.1 & 52.0 & 122.1 \\
\hline
\end{tabular}


height greater than $110 \mathrm{~cm}$ (Aleksandrovo 112, \#1071, and \#51) (data not shown). The most homogenous for height was Svejen 188. Among the species, the tallest bushes were found in $R$. centifolia.

The size of the rose bushes is associated with their productivity, size increase in subsequent years (sometimes up to the 10 th year) corresponds to increase in flower production. However, overall, the steepest increases in the size and productivity of rose bushes occur in the first 3 years (Topalov, 1962, 1978). Plant height and the diameter of the rose bushes are important for the industry because the rose flowers are picked manually. Despite the rigorous research on mechanizing flower picking, a feasible mechanical flower picking technology is yet to be developed (Nedkov and Attanassova, 2004).

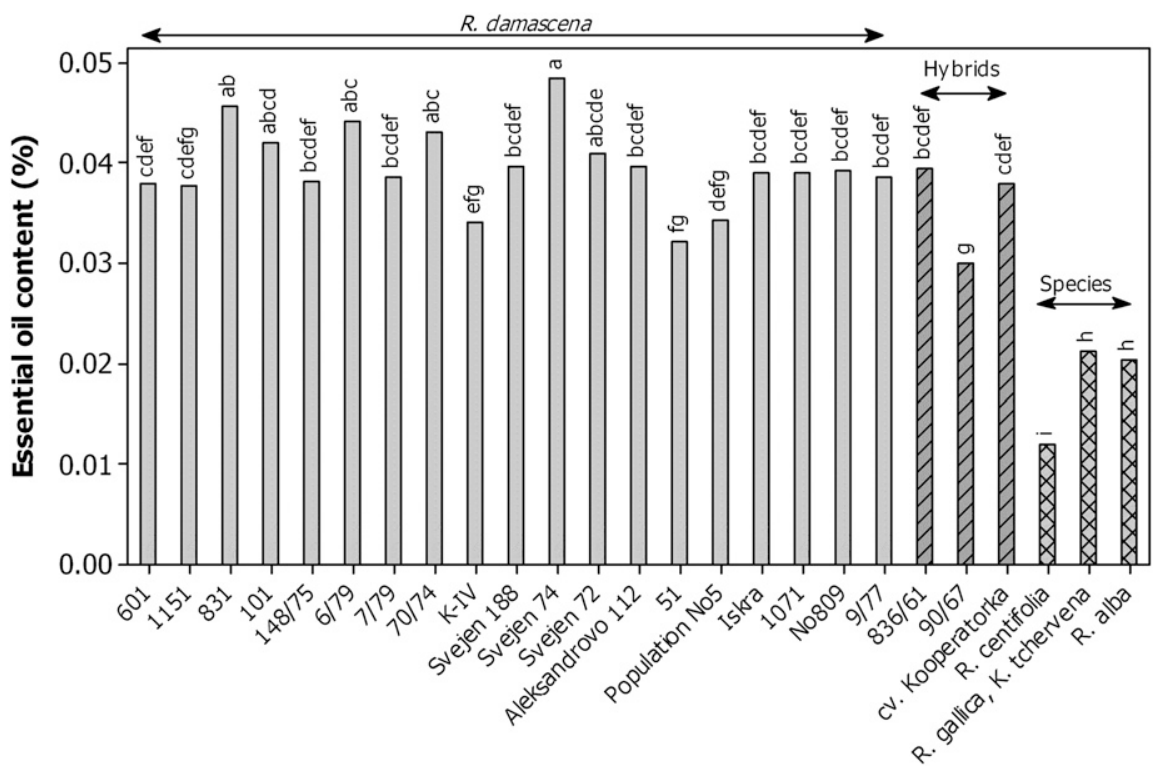

Fig. 1. Mean essential oil content (\%) from $19 R$. damascena clones, three hybrids, and three species. Means sharing the same letter are not significantly different at the $5 \%$ level of significance.
Mean bush diameter for all tested roses ranged from 32 to $105 \mathrm{~cm}$ (data not shown). $R$. damascena clones and cultivars could be grouped in relation to their diameter and form of the bushes: 1) upright bushes, $80 \mathrm{~cm}$ or less in diameter (\#1151, \#831, \#101, \#7/79, \#K-IV, Svejen 188, \#809, \#9/77, Iskra, Svejen 74, improved population \#5); 2) medium spread type, 80 to $100 \mathrm{~cm}$ diameter (\#601, \#148/75, \#70/74, Svejen 72, Aleksandrovo 112, and \#1071); and 3) widely spread type, greater than $100 \mathrm{~cm}$ in diameter (\#51 and \#6/79). Generally, rose bushes with erect growth habits are preferred because the flowers are easy to pick (Topalov, 1962). Rose flowers are picked manually between 0400 and $0700 \mathrm{HR}$, when the rose flowers open and the essential oil is present in the highest amount with the best quality (Topalov, 1962, 1978). Previous research on other cultivars of $R$. damascena found a positive correlation between the height of the rose bushes and their productivity (Singh and Kayiyar, 2001). In our study, the clones and cultivars with the highest bushes belong to the first two groups or relatively upright-type roses; however, for reasons indicated previously, producers prefer upright and relatively short bushes such as \#831, \#7/79, \#K-IV, Svejen 188, \#809, and Iskra. With the exception of $R$. alba, the tested hybrids and species had measured values below those measured in $R$. damascena clones (data not shown).

Rose flower morphology is one of the most conservative phenotypic traits, generally with significant differences between rose

Table 3. Oil constituents of the studied roses: means for 2002, 2003, and 2004 growing seasons.

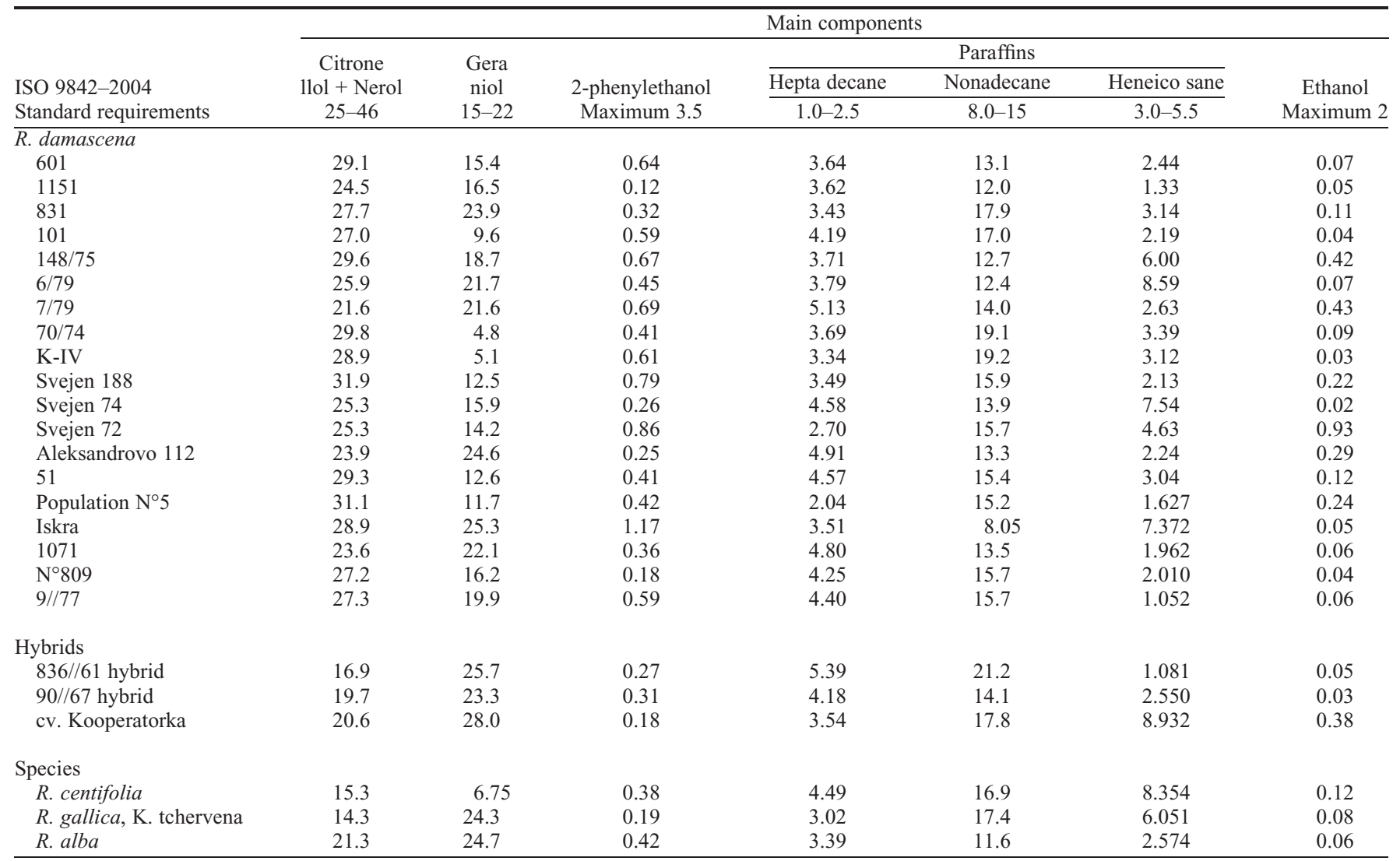




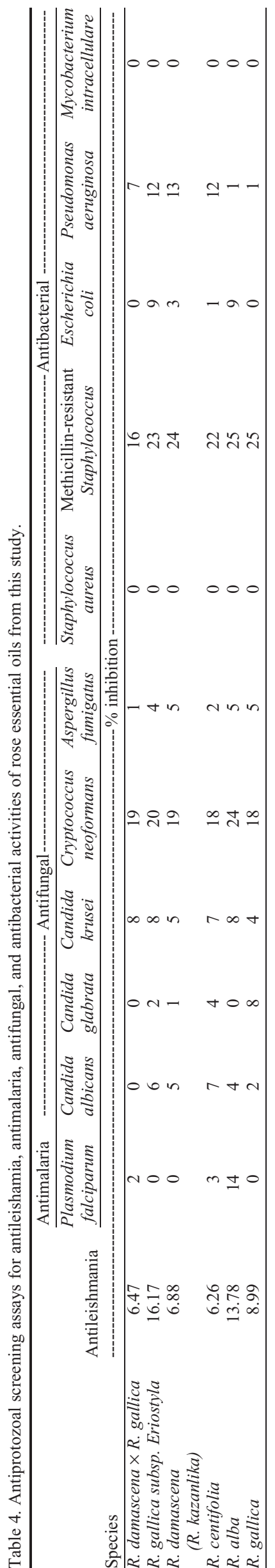

species, although the environment could have a modifying effect on the expression of this trait (Tabaei-Aghdaei et al., 2007; Topalov, 1978). The weight of an individual flower in oil-bearing roses is critically important because it is directly related to the efficiency of flower picking and the overall economy of the rose production (Topalov, 1978). Our results demonstrated that the weight of individual flowers of $R$. damascena was between 2.35 and $2.78 \mathrm{~g}$ with the highest values being the flowers of the control cultivar Iskra (data not shown). Of the hybrids, the heaviest flowers were found in $\# 836 / 61$, whereas of the species, the heaviest flowers were found in $R$. centifolia. The results from this study were similar to those of Tabaei-Aghdaei et al. (2007), who found rose flower weight variation between 1.39 and $2.78 \mathrm{~g}$.

One of the main objectives of the selection and breeding work in oil-bearing roses is the development of cultivars with high essential oil content, possibly greater than $0.05 \%$ in flowers. For the three cropping seasons, the average essential oil content in fresh flowers of $R$. damascena varied between $0.032 \%$ and $0.049 \%$, that for hybrid rose flowers between $0.03 \%$ and $0.039 \%$, whereas the oil content of the other rose species was $0.012 \%$ to $0.021 \%$ (Fig. 1). Our results demonstrated that Svejen 74 had higher essential oil concentration relative to the control cultivar Iskra. Furthermore, the essential oil concentration of rose accessions \#831, \#101, \#6/79, and \#70/74 was not different from that of Svejen 74 or from that of the control cultivar Iskra (Fig. 1). The essential oil concentration of the rest of the rose accessions from $R$. damascena was not different from that of the control cultivar Iskra. The essential oil concentration of hybrid 90/67 and the other species ( $R$. centifolia, $R$. gallica, and $R$. alba) was significantly lower than that of the control cultivar Iskra (Fig. 1).

Furthermore, the oil content of Bulgarian clones of $R$. damascena was higher than that of native $R$. damascena clones collected in Iran, which was reported to vary between $0.017 \%$ and $0.035 \%$ (Tabaei-Aghdaei et al., 2007). Of the hybrid roses, high essential oil content was found in \#836/61 and Kooperatorka.

The rose essential oil composition must meet the Bulgarian State Standard that was recently recognized as the international one (ISO 9842). We found differences in the number of the major essential oil constituents of the tested species and cultivars (Table 3 ).

L-citronellol, geraniol, and nerol are considered the main constituents of the rose oil (Topalov, 1978). These three components constitute the so-called "eleopten" part of the rose oil and provide the high fixing ability, which is directly related to the longevity of the perfume aroma and fragrances of the rose oil. The ISO 9842 rose oil standard requires the L-citronellol content to be within concentration ranges of $20 \%$ to $34 \%$ of the oil, nerol $5 \%$ to $12 \%$, and geraniol $15 \%$ to $22 \%$. The ratio among the three rose constituents, especially the sum of citronellol plus nerol, is important for rose oil quality and its marketing price. Our results indicated that within $R$. damascena, with the exception of $\# 7 / 79$ and Aleksandrovo, all cultivars and clones meet this quality requirement (Table 3). The concentration of geraniol indicates the differences existing among various cultivars and clones within one genotype. Regarding the concentration of paraffins (heptadecane, nonadecane, heneicosane), variation was also found, in some instances above the upper limit of ISO 9842 (Table 3).

The essential oils obtained from each of the rose species in this study did not show greater than $50 \%$ growth inhibition of the tested organisms at $50 \mu \mathrm{g} / \mathrm{mL}$ and were therefore deemed to be inactive with respect to antimicrobial, antibacterial, antifungal, antileishmania, and antimalarial activities (Table 4). Our results contradict earlier reports on antibacterial effect of $R$. damascena essential oil (Basim and Basim, 2003; Ozkan et al., 2004), most probably as a result of relatively lower concentrations tested in our study.

\section{Summary and Conclusions}

Although with a similar genotype, the various $R$. damascena clones expressed different phenotypes. Our results suggest that clones \#831, \#7/79, K-IV, Svejen 188, \#809, and Iskra are the most suitable for the establishment of commercial rose plantations in the region. Some of the clones of $R$. damascena have the potential to provide up to $0.05 \%$ average essential oil content. Hybrid \#836/61 had not only high essential oil content, but also a composition that is not typical for $R$. damascena. Hence, this clone may have the potential to be developed as a cultivar representing another type of rose essential oil. Generally, the essential oil content of $R$. damascena and the two hybrid roses, \#836/61 and cv. Kooperatorka, were similar and varied between $0.03 \%$ and $0.05 \%$, whereas the essential oil content of hybrid \#90/67 was lower than that of most clones. Overall, the highest essential oil content was found in $R$. damascena Svejen 74 (higher than in the control cultivar Iskra) and the lowest in $R$. alba. Essential oil constituents of all clones were determined. The essential oils from the rose species did not show greater than $50 \%$ activity and were deemed to be inactive with respect to antibacterial, antifungal, antimalarial, and antileishmania activities. Our research demonstrated that $R$. alba has a similar oil composition to that of $R$. damascena, making it a suitable genetic material for the development of new varieties.

\section{Literature Cited}

Astadjov, N. 1998. Study on Kazanlak rose clones with various colors of the rose petals. Rastenievudni Nauki. 9:27-32.

Basim, E. and H. Basim. 2003. Antibacterial activities of Rosa damascena essential oil Fitoterapia 74:394-396.

Furnis, B.S., A.J. Hannaford, P.W.G. Smith, and A.R. Tatchell. 1989. Vogel's textbook of practical chemistry. Ed. 5. Longman Scientific \& Technical, New York, NY. p. 171-175.

Kovatcheva, N., K. Rusanov, C. Lambev, and R. Todorova. 2004. Evaluierung der genetischen Ressourcen von olspendenden Rosenspezies in Bulgarien. Fachtagung fur Arznei und Gewurzpflanzen. Proc. Fachtagung fur Arznei 
und Gewurzpflanzen, 7-9 Sept. 2004, Jena, Germany.

Mikus, J. and D. Steverding. 2000. A simple colorimetric method to screen drug cytotoxicity against Leishmania using the dye Alamar Blue. Parasitol. Intl. 48:265-269.

Nedkov, N. and M. Attanassova. 2004. Essential oil and medicinal crops. Kameja Press, Sofia, Bulgaria.

Ozkan, G., O. Sadjic, N.G. Baydar, and H. Baydar. 2004. Antioxidant and antibacterial activities of Rosa damascena flower extracts. Food Sci. Technol. Intl. 10:277-281.

Rusanov, K., N. Kovatcheva, A. Atanassov, and I. Atanassov. 2005a. Microsatellite analysis of oilbearing roses which do not belong to the species Rosa damascena Mill Bulg. J. Agr. Sci. 11:1-9.

Rusanov, K., N. Kovatcheva, B. Vosman, S. Rajapakse, A. Atanassov, and I. Atanassov. 2005b. Macrosatellite analysis of Rosa damascena Mill. accessions reveals genetic similarity between genotypes used for rose oil production and old Damask rose varieties. Theor. Appl. Genet. 111:804-809.
SAS Institute Inc. 2008. SAS OnlineDoc 9.2. SAS Institute Inc., Cary, NC.

Singh, S.P. and R.S. Kayiyar. 2001. Correlation and path coefficient analyses for flower yield in Rosa damascena Mill. J. Herbs Spices Med. Plants 8:43-49.

Staikov, V. 1965. PhD diss., Agricultural Academy, Sofia, Bulgaria.

Tabaei-Aghdaei, S.R., A. Babaei, M. Khosh-Khui, K. Jaimand, M.B. Rezaee, M.H. Assareh, and M.R. Naghavi. 2007. Morphological and oil content variations amongst Damask rose (Rosa damascena Mill.) landraces from different regions of Iran. Sci. Hort. 113:4448.

Todorova, R., N. Kovatcheva, A. Dzurmanski, St. Stanev, and N. Nedkov. 2004. Das Institut fur Rosen, Aroma, und Arzneipflanzenforschung ein Forschungszentrum fur die Arznei, und gewurzpflanzenforschung in Bulgarien, Fachtagung fur Arznei und Gewurzpflanzen. Proc. Fachtagung fur Arznei und Gewurzpflanzen, 7-9 Sept. 2004, Jena, Germany.
Topalov, V. 1978. The Kazanlak rose and the rose production in Bulgaria. Christo G. Danov Press, Plovdiv, Bulgaria. p. 211.

Topalov, V.D. 1962. Essential oil and medicinal plants. Hr. G. Danov Press, Plovdiv, Bulgaria.

Zheljazkov, V.D. 1998. The oil-bearing rose, p. $317-$ 320. In: Phehlivanor, M., G. Moskov, B. Jankov, J. Terziev, V. Zheljazkov, and H. Yantcheva (eds.). Plant production. Academic Edition of Higher Institute of Agriculture, Plovdiv, Bulgaria.

Zheljazkov, V.D., C.L. Cantrell, B. Tekwani, and S. Khan. 2008. Content, composition, and bioactivity of the essential oil of three basil genotypes as a function of harvesting. J. Agr. Food Chem. 56:380-385.

Zheljazkov, V.D., Y. Yankuloff, R. Raev, S. Stanev, A. Margina, and N. Kovatcheva. 1996. Achievements in breeding on medicinal and aromatic plants in Bulgaria. Beitrage zur Zuchtungsforschung. 2:142-145.

Zlatev, C., A. Margina, and R. Tsvetkov. 2001. Production of the Kazanlak oil-bearing rose. Helicon Press, Kazanlak, Bulgaria. 